The Research Journal of the Costume Culture

[Original Article]
Received December 07, 2016

Accepted January 05, 2017

${ }^{\dagger}$ Corresponding author

(syshin0804@daum.net)

ORCID

Shin Su-yun

http://orcid.org/0000-0003-1304-366X

This work was supported by a research grant from Seoul Women's University (2016).

\section{Study of the influential factors of repurchase intention and word-of-mouth intention of men in their 20 's and 30's in social commerce \\ - Focused on social commerce characteristics and consumers' personal characteristics -}

\author{
Su-Yun Shin $^{\dagger}$ \\ Dept. of Clothing Science, Seoul Women's University, Korea \\ 소셜커머스에서 20 30대 남성의 재구매 의도와 \\ 구전 의도에 영향을 미치는 요인 연구 \\ - 소셜커머스 특성과 소비자 개인 특성을 중심으로 - \\ 신 수 연 $^{+}$ \\ 서울여자대학교 의류학과
}

\begin{abstract}
Social commerce is a kind of internet shopping mall in which consumers purchase the products with other consumers through mutual interactions including the development of SNS(social network service). Social commerce has expanded rapidly as a mainstream online shopping mall over the past five years driving consumers to purchase more fashion products providing the cheaper prices than open market internet shopping mall. The purpose of this study is to identify the important parameters of social commerce characteristics and consumer characteristics that affect repurchase intention and wordof-mouth intention. A 221 survey questionnaire was distributed to men in their 20's and 30's who live in Seoul metropolitan area. The data were analyzed utilizing Cronbach's $\alpha$, factor analysis, and regression analysis using the SPSS 18.0 program. The results revealed, first, that in terms of social commerce characteristics, three variables(website reputation, interactivity, and product scarcity) influenced repurchase intention. Among them, website reputation identified as the most important factor influencing repurchase intention and word-of-mouth intention. Second, with regard to consumer characteristics, interest and a tendency toward impulse buying affected the repurchase intention, and interest and internet shopping experience have influenced the word-of-mouth intention. Among three variables interest in social commerce identified as the key factor affecting both repurchase intention and word-of-mouth intention. The results of the study provide the practical implications and suggest the business strategies to enhance social commerce in the future by identifying the key social commerce characteristics and consumer characteristics that influence male consumers' buying behaviors.
\end{abstract}

Keywords: career men in 20's-30's(20 30대 직장 남성), social commerce(소셜 커머 스), purchase behaviors(구매행동), fashion product(패션 제품) 


\section{Introduction}

소셜커머스(social commerce)는 전자상거래의 일종으 로 소셜미디어(social media)와 e-커머스(e-commerce)가 합쳐져서 만들어진 용어로 소셜 쇼핑(social shopping)이 라고도 불리운다(Wang \& Kwon, 2012). 이러한 소셜 커머스는 포름, 커뮤니티, 리뷰, 사용자 추천 등을 통 해 소비자들이 구매의사를 표현하고, 다른 소비자들 의 적극적인 참여와 구매경험을 증진시킨다(Stephan \& Toubia, 2010). 소셜커머스는 크게 소셜 링크형, 소 셜 웹형, 오프라인 연동형, 공동구매형으로 나눌 수 있는데, 2008년 그루폰이 설립된 후 세계적으로 공동 구매형 소셜커머스가 급성장하고 있으며, 한국에서도 2010년 소셜커머스 시장 출범이후 쿠팡, 위메프 등의 공동구매형 소셜커머스를 중심으로 발전하였다(An, 2013; Wang \& Kwon, 2012).

최근 5 년간 국내 온라인 쇼핑몰 시장은 매년 두 자 리 수 이상의 성장률을 보이며 2015년 국내 온라인 쇼핑몰 거래액은 53조 9340 억원으로 이미 대형 마트 의 거래액인 48 조 6350 원을 앞지르고 있다(Ahn, 2015). 2015년 온라인 쇼핑몰 시장규모를 좀 더 세분 화하여 살펴보면 $\mathrm{PC}$ 기반 인터넷 쇼핑몰이 29조원, 모바일 커머스가 24조원으로 2013년 6조 5596억원에 머무르던 모바일 커머스 시장은 2년 사이 약 4 배의 거래액의 증가를 보이면서 온라인 쇼핑의 쌍두마차 로 급부상하고 있다(Kang, 2016). 그 중에서도 소셜 커머스는 오픈 마켓과 달리 불특정 다수 업체가 비슷 한 제품을 파는 형태가 아닌 소셜커머스 MD가 추천 하는 소수의 상품을 판매하여 큐레이션(curation) 차 별화를 통한 모바일 거래의 최적화된 온라인 쇼핑의 형태로 빠른 배송과 가격파괴를 모토로 출범 5 년 만 에 거래액이 2011년 500억원에서 2015년 6조900억 원으로 100 배 이상 증가하는 초고속 성장 속에 온라 인 쇼핑몰 성장의 견인차 역할을 하고 있다(Jung, 2014; Park, 2015). 우리나라에서는 2010년 3월 위폰 (wipon.co.kr)에서 소셜커머스 서비스를 시작하여 2011 년에는 200 개 이상의 업체가 생겼지만, 현재는 소셜커 머스 대표업체인 쿠팡, 티켓몬스터, 위메프가 소셜 커 머스 시장을 주도하고 있다(Wang \& Kwon, 2012). 물 론 빠른 성장과 함께 영업 손실도 같이 증가하여 우 려의 목소리도 크지만, 적자는 프랫폼 장악을 위한
성장통으로 모바일 쇼핑의 선두 주자인 소셜커머스 의 시장 가능성을 긍정적으로 평가하고 있다 $(\mathrm{Kim}$, 2016). 실제로 쿠팡은 모바일 커머스 시장에서의 선 전을 토대로 2014년 미국 투자전문 회사인 브랙록 등 으로부터 약 4,400억원의 자금을, 2015년 6월에는 일 본 소프트뱅크에서 1 조 1,000 억원의 자금을 유치하는 데 성공했다. 또한 위메프도 넥슨의 지주사 엔엑스씨 로부터 1,000 억원 규모의 자금을 투자받는데 성공했 다(Kim, 2016; Park, 2015).

지금까지의 소셜커머스에 관한 선행연구들은 소 셜커머스가 전자상거래의 하나의 유형으로 자리 잡 기 시작한 2011년도부터 비교적 활발하게 진행되고 있다. 초기에는 소셜커머스 시장현황 및 비즈니스 모델에 관한 연구(Jin \& Lim, 2012; Lee, 2011)가 일 부 진행되었고, 최근에는 소셜커머스에서의 다양한 소비자 행동에 관한 연구가 주를 이루고 있다. 이를 세분화해 보면 소비자의 구매 만족, 구매 의도, 재구 매 의도에 관한 변인을 밝힌 연구(Hong \& Lee, 2015; Kim, 2013; Kim \& Chung, 2015; Lee, 2013; Lee, 2014; Lee, Chung, \& Jeun, 2012; Woo \& Hwang, 2013), 충동구매와 충성도에 영향을 미치는 변인 연 구(An, 2013; Chen, 2012; Lee \& Shin, 2013), 소셜 커머스와 오픈 마켓의 이용 경험을 비교, 분석한 연 구가 있고(Chae, Lim, \& Kang, 2015), 최근에는 모 바일 쇼핑앱 사용자를 대상으로 모바일을 중심으로 한 소셜커머스 구매행동을 다룬 연구가 일부 진행되 었다(Baek \& Han, 2015; Choi \& Lee, 2016). 위의 선행연구를 종합해 보면 지금까지의 대다수의 연구 가 여성을 대상으로 하여 소비자의 쇼핑가치, 쇼핑 성향, 지각된 위험, 이용동기, 구매만족도가 소셜커 머스 구매 행동에 미치는 영향에 대한 연구를 중심 으로 진행되어 소셜커머스에서 큰 손으로 급부상하 고 있는 남성소비자에 대한 연구는 부족한 실정이 다.

따라서 본 연구에서는 전체 남성에서 소셜커머스 구매의 $70 \%$ 이상을 차지하고 있는 20 30대 남성 소 비자를 대상으로 하여(Kim, 2016) 소셜커머스 특성 과 소비자 특성이 소셜커머스에서 재구매 의도와 구 전의도에 미치는 영향을 밝히고, 최근 전자상거래 시 장에서 급부상하고 있는 남성 소비자를 위한 마케팅 전략의 수립에 기여하고자 한다. 


\section{Theoretical Background}

\section{Social commerce concept and current issues}

2010년 뜨거운 관심을 보이고 등장한 소셜커머스 (social commerce)는 2015년에 6조 900억원으로 출범 5 년 만에 100 배 이상의 빠른 성장을 보이며 온라인 쇼핑 성장의 견인차 역할을 하고 있다(Park, 2015). 소셜커머스(social commerce)는 전자상거래의 일종으 로 소셜미디어(social media)와 e-커머스(e-commerce) 가 합쳐져서 만들어진 용어로 소셜커머스라는 용어 는 야후의 장바구니 서비스를 통하여 2005년도에 처 음 소개되었으며, 2008년에 미국 시카고의 공동구매 형 소셜커머스 업체 그루폰이 레스토랑의 피자가격 을 $50 \%$ 로 대폭 할인하여 판매 후 성공을 거둔 후 본 격적으로 발달하기 시작하였다(An, 2013; Bae, 2013). 소셜커머스는, 기존의 전자상거래와의 다소 차이가 있는데 기존의 전자 상거래가 소비자가 제품이나 서 비스를 구매할 때 소비자 스스로 정보를 수집하고 비 교 분석해야 했다면 소셜커머스는 인맥과 구전을 통 한 정보획득과 설득 과정이 소셜미디어를 통해서 이 루어진다는 점이다. 소비자들이 $\mathrm{SNS}$ 를 통하여 자발 적으로 상품을 홍보하고, 일정 인원이 모아지면 가격 을 할인 받는 공동구매방식은 소비자 입장에서는 저 렴한 가격으로 제품을 구매할 기회를 얻게 되면서 소 셜커머스 업체에서는 일반적인 상품판매에 들어가는 광고와 마케팅 비용이 거의 들지 않고 수수료 획득 및 고객 확보가 용이하여 소비자와 소셜커머스 업체 가 서로 win-win 할 수 있는 구조이다(Han, Song, \& $\mathrm{Lim}, 2011)$. 즉, 소셜커머스는 페이스북, 트위터 등과 $\mathrm{SNS}$ 와 결합하여 실시간성과 동시에 확산성을 가지면 서 기존의 인터넷 쇼핑몰과는 달리 SNS를 이용하여 온라인과 오프라인을 연계하여 통합, 확장시킬 수 있 어 그 파급효과가 크다고 하였다(Goo, 2011). 소셜커 머스는 크게 4가지 유형(소셜 링크형, 소셜 웹형, 공 동구매형, 오프라인 연동형)이 있는데, 첫째, 소셜 링 크형은 가장 기본적인 유형으로 소셜커머스 사이트 에서 클릭 한 번으로 페이스북, 트위터 등의 소셜네 트 워크 서비스로 이동할 수 있게 링크를 하는 방식 이다. 둘째, 소셜 웹형은 소셜커머스와 SNS가 결합된 방식으로 소셜커머스 사이트에서 SNS의 기능을 구현 해 주는 방식이다. 셋째로, 공동구매형은 소셜커머스
의 대표적인 유형으로 쿠팡, 위메프와 같은 공동구매 형 사이트가 소셜 네트워크 서비스와 결합된 형태이 다. 마지막으로, 오프라인 연동형은 오프라인 공간을 네트워킹이 가능한 단말기와 소셜 네트워크로 연동시 키는 방식이다(Lee \& Shin, 2013; Park \& Koh, 2013). 소셜커머스에서 거래되는 제품군은 초기에는 공연, 식음료, 미용과 관련한 제품군이 주를 이루었으 나 현재는, 여행, 패션, 가전 등의 제품군이 늘어나면 서 다양한 상품군으로 확대되고 있으며, 특히 패션제 품의 비중이 커지고 있어 국내 유명 소셜커머스 업체 들은 패션 제품의 비중을 강화하고 있다(Kim, 2013). 물론 짧은 시간에 급성장한 유통 플랫폼인 만큼 할인 율 과장, 개인정보 노출, 영업 손실 등 풀어야 할 과 제도 많지만, 그럼에도 불구하고 국내 대기업 유통업 체들은 앞으로 소셜커머스 시장이 더욱 크게 성장 할 것으로 보고 소셜커머스 시장에 진출하고 있어 업체 간 경쟁은 더욱더 치열해지고(Kim \& Chung, 2015), 이에 따라 경쟁우위를 차지하기 위한 차별화된 마케 팅 전략이 필요한 시점이라고 하겠다.

\section{Social commerce characteristics}

Lee(2012)는 소셜커머스 사이트에서 패션제품 구 매시 사이트 안정성, 사이트 편리성, 재미 및 즐거움, 상호작용성이 고객 충성도와 재구매 의도에 영향을 미친다고 하였고, 특히 소셜커머스의 재미 및 즐거움 을 높이기 위해서는 다양한 이벤트의 진행이 필요하 다고 하였다. Jin and Lee(2012)는 정보성, 상품의 다 양성, 소통가능성, 반응성, 가격성과 같은 소셜커머스 의 특성이 소비자의 재구매 의도에 영향을 미치는 변 인이라고 하였다. Lee(2014)는 소셜커머스에서 패션 제품판매 시 가격에 민감하게 대응하여야 하고, 쿠폰 이나 다양한 할인이벤트, 마일리지 적립 등의 활발한 판매 촉진과 함께 제품 정보제공, 판매 서비스에 대 한 빠른 고객응대를 통해 재구매 의도를 높여야 한다 고 하였다. Lee et al.(2012)은 적절한 가격, 제품일치, 편리한 결제, 구매시 혜택, 빠른 주문처리와 배송 등 이 재구매 의도에 영향을 미친다고 하였다. Kim (2012) 의 연구에서는 인터넷 쇼핑 사이트는 물리적 공간이 아닌 가상의 공간으로 소비자들은 불확실성과 위험 을 느끼기 때문에 긍정적이고 평판이 좋은 소셜커머 스 사이트는 구매행동에 중요한 영향을 미친다고 하 
였다. 또한 소셜커머스에서 시간과 제품 수량이 제한 되어 있음을 알리는 것과 같은 희소성 메시지는 소자 들에게 심리적 압박감을 자극하여 구매를 유도할 수 있다고 하였다(Park, Kim, Funches, \& Foxx, 2012; Son, 2013).

이상의 선행연구를 살펴본 결과, 소셜커머스의 사 이트 명성, 가격할인, 상호작용성은 소비자의 재구매 의도를 자극시키며, 소셜커머스에서 시간한정과 수량 한정의 희소성 메시지는 오픈 마켓과는 구별되는 특 징으로 소비자들의 구매행동을 예측할 수 있는 변인 으로 사료된다.

\section{Consumer's personal characteristics}

Han and Park(2000)의 연구에서는 흥미란 어떤 대 상, 활동, 경험 등에 지속적으로 몰두하는 행동경향이 라고 하였다. 즉, 개인의 흥미는 자발적으로 동기가 일어나 스스로 특정대상에 이끌려 감정적으로 동요 되는 정도를 말하며, 인터넷에서의 흥미도는 인터넷 매체나 SNS를 이용하여 쇼핑하는 것에 대한 관심의 정도를 의미한다고 하였다. Baek(2008)은 소비자가 인터넷을 통하여 제품을 구매할 시 인터넷 사이트에 대한 흥미와 호기심이 높을수록 구매율도 높게 나타 난다고 하였다. Park et al.(2012)은 소셜커머스에서 인구통계적 특성에 따라 구전효과가 다르게 나타난 다고 하였는데, 대학생들이 직장인보다 $\mathrm{SNS}$ 를 통해 보다 활발한 정보교환을 하기 때문에 캐쥬얼 의류 구 매 시 구전 효과가 높게 나타난다고 하였다. 또한 Lee et al.(2012)의 연구에 따르면 패션 소셜커머스 만족 도에서는 인구통계학적 변인은 유의한 영향을 미치 지 못했으나, 재구매 의도에서는 직업에 따른 차이를 보였는데, 여대생들이 직장여성들에 비해 패션 소셜 커머스를 통해 재구매할 의사가 높다는 결과를 나타 냈다. Yang and Choi(2014)는 소셜커머스에서 패션 제품을 구매하는 소비자는 $\mathrm{SNS}$ 를 통해 지인들과 정 보교환을 활발히 하고, $\mathrm{SNS}$ 를 활용한 상효교류를 중 요시하기 때문에 구전의도를 높이기 위해서는 그 선 행 변수로써 구매만족을 높여야 한다고 하였다. Cho, Shin, and Song(2012)은 소셜커머스에서 구매만족에 영향을 미치는 변인으로 인터넷 쇼핑경험이 중요하 여 인터넷에서의 쇼핑경험이 많은 소비자일수록 SNS 에서의 지인들과의 정보교류를 통해 소셜커머스를
이용할 확률이 높다고 하였다. 충동구매성향은 제품 을 보자마자 심사숙고 없이 즉각적인 구매행동을 하 는 성향으로 오프라인 매장보다 시간과 공간의 제약 을 받지 않는 가상의 공간에서 의류구매를 할 때 더 활발히 일어난다고 하였고(Shin, 2012), Hwang and $\operatorname{Baek}(2009)$ 은 인터넷 쇼핑몰에서 공동구매를 기획할 때 소비자의 충동구매성향에 따라 의류제품에 대한 구매의도가 다르게 나타나기 때문에 이에 따라 적절 한 마케팅 전략을 수립해야 한다고 하였다.

이상의 선행연구를 고찰한 결과, 소비자의 개인적 특성요인 중 흥미도, 충동구매성향 및 인터넷 쇼핑경 험은 소셜커머스에서 재구매 의도와 구전의도를 측 정하는 선행변수로써 그 의미가 있다고 하겠다.

\section{Repurchase intention and word-of-mouth in- tention}

재구매 의도는 제품이나 서비스를 제공 받은 후 긍 정적 평가를 토대로 하여 다시 그 제품이나 서비스를 재구매하려는 정도로 정의할 수 있다. 따라서 재구매 의도는 소비자가 좋은 감정으로 특정 제품이나 상점 에 대해서 지속적으로 상호작용을 유지할 것인가에 대한 의미이며, 온라인 쇼핑몰과 같은 가상 공간에서 의 재구매 의도는 매우 중요한 애호도의 표현이라고 하였다(Shin \& Yoh, 2013). Kim and Oh(2002)는 고 객이 과거의 경험과 미래의 기대를 바탕으로 현재의 서비스를 반복해서 이용할 가능성 또는 의도라고 하 였다. 재구매 의도는 기존고객을 유지하는 비용이 신 규고객을 창출하기 위하여 투자하는 비용보다 횔씬 경제적이므로 고객의 재구매 의도를 높이는 것은 기 업의 성공을 이끄는 중요한 요인 중의 하나라고 할 수 있다(Crego \& Schiffrin, 1995).

구전(Word-of-Mouth: WOM)은 제품과 서비스 평 가에 관심을 가지는 개인 당사자들 간의 비공식적 커 뮤니케이션으로 정의할 수 있다. 고객은 공식적이고 상업적인 정보를 제공하는 광고보다도 비공식적 의 사소통으로 얻은 정보를 더 신뢰하는 것으로 나타나, 기업은 소비자들의 구전의도를 주목을 해야 하며, 구 전이 매출에도 영향을 미친다고 하였다(Dellarocas, 2003; Kozinets, De Valck, Wojnicki, \& Wilner, 2010). 구전은 낮은 비용과 소비자의 자발적 참여로 제품구 매 시 소비자들의 저항을 낮추어 온라인에서 특히 활 
발하게 사용할 수 있는 마케팅 기법으로(Trusove, Buckling, \& Pauwels, 2009), 구전에는 긍정적 구전과 부정적 구전이 있는데, 제품구매 후 만족한 소비자는 긍정적인 구전을 하게 되고, 이는 고객확보를 할 수 있는 중요한 수단이 될 수 있다(Wangenheim \& Bayón, 2007). 온라인 시장의 규모가 커지고 특히 소셜커머 스는 특성상 인맥과 구전을 통한 정보획득과 설득과 정이 소셜미디어를 통해 이루어지기 때문에, 소셜커 머스에서 소비자의 구전의도를 예측하는 변인을 밝 히는 것은 그 의의가 있다고 하겠다.

\section{Research Methods}

\section{Research hypotheses}

본 연구는 소셜커머스에서 20 30대 남성이 패션 제품을 구매할 시 재구매 의도와 구전의도에 미치는 요인에 대해 연구하고자 한다. 이를 위하여 독립변인 을 소셜커머스의 특성(사이트의 명성도, 상호작용성, 제품 희소성의 메시지, 가격할인)과, 소비자 개인의 특성(흥미도, 충동구매성향, 인터넷 쇼핑 경험)으로 구성하여 재구매 의도와 구전의도에 미치는 요인을 살펴보았다(Fig. 1). 이를 위한 연구의 가설은 다음과 같다.

H1-1(H2-1): 소셜커머스에서 의류제품 구입 시, 사 이트명성도가 높을수록 재구매의도(구전의도)가 높게 나타날 것이다.

H1-2(H2-2): 소셜커머스에서 의류제품 구입 시, 상

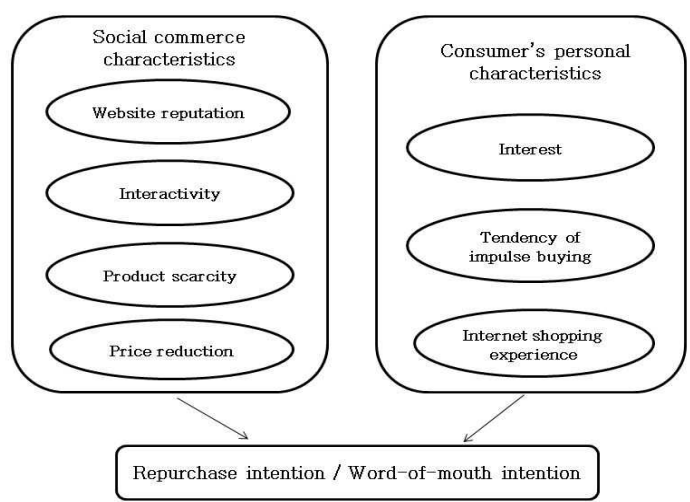

<Fig. 1> Research model
호작용성이 높을수록 재구매의도(구전의도)가 높게 나타날 것이다.

H1-3(H2-3): 소셜커머스에서 의류제품 구입 시, 제 품희소성이 높을수록 재구매의도(구전의도)가 높게 나타날 것이다.

H1-4(H2-4): 소셜커머스에서 의류제품 구입 시, 가 격할인이 높을수록 재구매의도(구전의도)가 높게 나 타날 것이다.

H3-1(H4-1): 소셜커머스에서 소비자의 흥미도가 높 을수록 재구매의도(구전의도)가 높게 나타날 것이다.

H3-2(H4-2): 소셜커머스에서 소비자의 충동구매성 향이 높을수록 재구매의도(구전의도)가 높게 나타날 것이다.

H3-3(H4-3): 소셜커머스에서 소비자의 인터넷 쇼 핑경험이 많을수록 재구매의도(구전의도)가 높게 나 타날 것이다.

\section{Measurement tools and data analysis}

소셜커머스 특성에 대한 변인(사이트의 명성도, 상 호작용성, 제품 희소성의 메시지, 가격할인)은 Hong and Lee(2015), Kim and Son(2013), Lee(2013), Lee and Shin(2013)의 선행연구를 참고로 하여 총 16문항 으로 구성하였다. 소비자의 개인적 특성에 관한 변인 (흥미도, 충동구매성향, 인터넷 쇼핑경험)은 Chen(2012), Cho et al.(2012), Lee and Shin(2013)의 연구를 기초 로 하여 총 14 문항으로 구성하였다. 재구매 의도와 구전 의도에 관한 측정항목은 Bae(2013), Jin and Lee(2012), Lee(2014), Yang and Choi(2014)의 선행연구를 참고 및 수정 - 보완하여 각 3 문항씩 구성하였다. 소셜커머 스에서의 구매 행동은 Kim and Chung(2015)과 Yang and Choi(2014)의 연구에서 사용한 문항들을 참고하 여 소셜커머스 제품 구매비용, 주로 구매하는 패션제 품, 구매 빈도, 이용업체, 최초방문 경로, 접속 경로 등으로 구성하여 측정 문항은 명명척도로 측정하였 다. 소셜커머스 특성, 소비자의 개인적 특성, 재구매 의도, 구전의도와 관련한 문항은 5점 리커트 척도로 측 정하였고, 각 연구 변수에 대한 조작적 정의는 〈Table 1)에 제시하였다.

본 연구의 자료 분석을 위하여 Cronbach's $\alpha$, 빈도 
$<$ Table 1> Operational definition

\begin{tabular}{|c|c|c|c|}
\hline \multicolumn{2}{|r|}{ Variables } & Operational definition & Item $n$. \\
\hline \multirow{4}{*}{$\begin{array}{c}\text { Social } \\
\text { commerce } \\
\text { characteristics }\end{array}$} & Website reputation & $\begin{array}{l}\text { Degree of the recognition of the social commerce to } \\
\text { consumers. }\end{array}$ & 4 \\
\hline & Interactivity & $\begin{array}{l}\text { Degree of various effort of social commerce to satisfy } \\
\text { customers such as } 1: 1 \text { customized service, etc. }\end{array}$ & 4 \\
\hline & Product scarcity & $\begin{array}{l}\text { The message of the limited time and quantity given by a } \\
\text { social commerce. }\end{array}$ & 5 \\
\hline & Price reduction & Discounts rates offered by social commerce & 3 \\
\hline \multirow{3}{*}{$\begin{array}{c}\text { Consumer's } \\
\text { personal } \\
\text { characteristics }\end{array}$} & Interest & $\begin{array}{l}\text { Attention and interest towards purchasing through a social } \\
\text { commerce. }\end{array}$ & 6 \\
\hline & $\begin{array}{l}\text { Tendency of } \\
\text { impulse buying }\end{array}$ & $\begin{array}{l}\text { Tendency of buying products immediately without } \\
\text { consideration }\end{array}$ & 4 \\
\hline & Internet shopping experience & Experience in consumer goods purchased via the Internet & 4 \\
\hline \multicolumn{2}{|c|}{ Repurchase intention } & $\begin{array}{l}\text { Repurchase willingness after buying the product in social } \\
\text { commerce based on positive estimation }\end{array}$ & 3 \\
\hline \multicolumn{2}{|c|}{ Word-of Mouth-intention } & Recommendation willingness about social commerce to others. & 3 \\
\hline
\end{tabular}

분석, 요인분석, 회귀분석을 실시하였으며, 활용한 통 계 패키지는 SPSS 18.0이다.

\section{Research subjects and data collection}

본 연구는 최근 1 년 동안 소셜커머스에서 패션제 품을 구매한 경험이 있으며, 서울과 경기 및 수도권에 거주하고 있는 20 30대의 남성을 대상으로 편의 표 본 추출 방법을 사용하여 설문조사를 실시하였다. 예 비조사는 2016년 5월 9일부터 5월 16일까지 실시되었 으며, 50 부의 설문지가 수거되었다. 본 조사는 2016 년 6월 1일부터 6월 21일까지 실시하였으며, 총 270 부의 설문지를 배포하여 응답이 불성실하거나 부정 확한 설문지 49 부를 제외하고, 총 221 부를 자료 분석 에 사용하였다.

\section{Result Result and Discussion}

1. Buying behaviors of men in 20's and 30's in soical commerce

설문조사를 통해 회수된 221 명의 연구대상자의 소 셜커머스에서의 구매행동은 다음과 같다. 먼저, 소셜 커머스를 통하여 지난 1년간 패션제품(신발, 가방, 액 세서리류 포함)을 구매한 경험에 대해서는 1 5번이 125 명(56.6\%), 6 10번이 49명(22.1\%)으로 약 $80 \%$ 를
차지하였고, 11 20번이 19명(8.6\%)으로 나타났으며, 20 번 이상도 28 명(12.7\%)으로 20 30대 남성소비자의 소셜커머스 이용률이 비교적 활발함을 알 수 있었다. 1 회 평균 구매 금액을 살펴보면 3만원 미만이 45명 (20.4\%), 5만원 미만이 78명(35.5\%), 5 10만원 미만 이 56 명(25.3\%)으로 약 $80 \%$ 이상을 차지하였고, 10 20 만원 미만이 32명(14.5\%), 20만원 이상이 10명(4.5\%) 으로 전체의 $20 \%$ 정도를 구성하였다. 주로 구입하는 패션제품에 대해서는 의류(상의, 하의 등)가 128 명 (57.9\%), 액세서리류가 41명(18.6\%), 신발(운동화, 구 두 등)이 39명(17.6\%), 가방이 13명(5.9\%)으로 나타나, 과반수 이상이 의류 구매를 하고 있는 것으로 나타났 다. 자주 이용하는 소셜커머스는 쿠팡이 119명(53.8\%) 으로 과반수 이상을 차지하였으며, 그 다음으로 위메 프 46명(20.8\%), 티켓 몬스터 32명(14.5\%), 쿠차 16명 16 명(7.2\%), 기타 4명(1.8\%)으로 나타났다. 소셜커머 스를 처음 방문하게 된 경로에 대해서는 인터넷 광고 가 73명(33.0\%)으로 가장 높게 나타났지만, 소셜커머 스의 특성상 본인의 직접 경험이 58 명 $(26.2 \%)$, 구매경 험자의 조언이 42 명(19.0\%)으로 비교적 높은 비율을 차지하였다. 소셜커머스 이용 시 주로 접속하게 되는 경로에 대해서는 스마트폰앱이 143 명(60.6\%), 컴퓨터 인터넷 접속이 75 명(33.9\%), SNS 서비스(문자, e-mail) 가 12 명(5.4\%)으로 나타나, 20대 여성은 스마트폰 앱 
보다 컴퓨터 인터넷 접속을 더 자주 이용한다는 Lee and Shin(2013)의 결과와 다르게 나타났다. 이는 남 성은 패션제품 구매 시 다양한 제품을 더 많이 볼 수 있는 PC 기반의 인터넷 쇼핑몰보다는 큐레이션 커머 스의 성향이 더 큰 스마트폰 앱을 선호한다고 할 수 있다.

\section{Social commerce characteristics}

20 30대 남성의 소셜커머스 특성의 하위차원을 분 류하기 위해 탐색적 요인분석을 실시하였으며, 결과
는〈Table 2〉와 같다. 분석방법으로는 Varimax 회전 법의 주성분 분석(principle component analysis)을 실 시하였으며, 총 16 개의 문항 중 4 개의 요인을 추출하 였다. 이 요인들은 전체 변량의 $68.952 \%$ 의 설명력을 가지고 있으며, 신뢰도를 나타내는 Cronbach's $\alpha$ 값 이 .70 이상으로 나타나 신뢰할만 하였다. 소셜커머스 인식에 관한 요인 1은 “잘 알려지지 않은 소셜커머스 사이트는 유명한 사이트보다 신뢰가 가지 않는다.”, "내가 주로 사용하는 소셜커머스 사이트는 주변사람 들도 잘 알고 있다.", “내가 주로 사용하는 소셜커머

$<$ Table 2> The result of factor analysis about social commerce characteristics

\begin{tabular}{|c|c|c|c|c|c|c|}
\hline Factor & Measurement item & $\begin{array}{c}\text { Factor } \\
\text { loadings }\end{array}$ & $\begin{array}{l}\text { Eigen } \\
\text { value }\end{array}$ & $\begin{array}{c}\text { Variance } \\
(\%)\end{array}$ & $\begin{array}{l}\text { Accumulative } \\
\text { variance }(\%)\end{array}$ & $\begin{array}{l}\text { Reliability } \\
\quad(\%)\end{array}$ \\
\hline \multirow{4}{*}{$\begin{array}{l}\text { Website } \\
\text { reputation }\end{array}$} & $\begin{array}{l}\text { I trust more famous websites than not-famous } \\
\text { websites. }\end{array}$ & .823 & \multirow{4}{*}{3.329} & \multirow{4}{*}{20.807} & \multirow{4}{*}{20.807} & \multirow{4}{*}{.902} \\
\hline & The social commerce I use is well-known by others. & .876 & & & & \\
\hline & $\begin{array}{l}\text { I usually use the frequently exposed social } \\
\text { commerce in the media. }\end{array}$ & .834 & & & & \\
\hline & $\begin{array}{l}\text { I have a tendency to buy the fashion product in } \\
\text { famous social commerce. }\end{array}$ & .802 & & & & \\
\hline \multirow{4}{*}{ Interactivity } & $\begin{array}{l}\text { This social commerce is very good at } 1: 1 \text { customized } \\
\text { service. }\end{array}$ & .739 & \multirow{4}{*}{2.823} & \multirow{4}{*}{17.642} & \multirow{4}{*}{38.449} & \multirow{4}{*}{.836} \\
\hline & $\begin{array}{l}\text { This social commerce is well communicated through } \\
\text { purchase reviews, a private club, etc. among users. }\end{array}$ & .817 & & & & \\
\hline & $\begin{array}{l}\text { This social commerce is very excellent to confirm } \\
\text { order process through SMS and E-mail. }\end{array}$ & .832 & & & & \\
\hline & $\begin{array}{l}\text { This social commerce responds very quickly to } \\
\text { customers questions and complains. }\end{array}$ & .723 & & & & \\
\hline \multirow{5}{*}{$\begin{array}{l}\text { Product } \\
\text { scarcity }\end{array}$} & $\begin{array}{l}\text { I desire to buy fashion product to be sold out soon } \\
\text { in social commerce. }\end{array}$ & .692 & \multirow{5}{*}{2.504} & \multirow{5}{*}{15.650} & \multirow{5}{*}{54.099} & \multirow{5}{*}{.763} \\
\hline & $\begin{array}{l}\text { I need to buy the product immediately because of } \\
\text { available time of purchase. }\end{array}$ & .687 & & & & \\
\hline & $\begin{array}{l}\text { I have to purchase the fashion product when I see } \\
\text { 'Last call' message in social commerce. }\end{array}$ & .697 & & & & \\
\hline & $\begin{array}{l}\text { I went to purchase the fashion product if the } \\
\text { quantity is limited in social commerce. }\end{array}$ & .677 & & & & \\
\hline & $\begin{array}{l}\text { I desire to purchase the fashion product if the } \\
\text { product types are limited in social commerce }\end{array}$ & .660 & & & & \\
\hline \multirow{3}{*}{$\begin{array}{c}\text { Price } \\
\text { Reduction }\end{array}$} & $\begin{array}{l}\text { I can save the money for shopping fashion } \\
\text { product in social commerce. }\end{array}$ & .776 & \multirow{3}{*}{2.377} & \multirow{3}{*}{14.853} & \multirow{3}{*}{68.952} & \multirow{3}{*}{.873} \\
\hline & $\begin{array}{l}\text { I think the product price is less expensive in } \\
\text { social commerce than in Internet shopping mall. }\end{array}$ & .818 & & & & \\
\hline & I can buy value pricing product in commerce. & .845 & & & & \\
\hline
\end{tabular}


스 사이트는 언론에서 많이 접해본 사이트이다."와 같이 소셜커머스 사이트의 인지도와 명성도와 관련 된 문항들로 구성되어 ‘사이트 명성도'로 명명하였으 며, 요인 2는 “소셜커머스는 1:1 맞춤형 고객상담이 잘 운영되고 있다”, “소셜커머스는 동호회, 사용후기 등 사용자간의 의사소통과 정보교류가 수월하다.”, “소 셜커머스는 고객의 질문과 불만사항에 빠르게 대처 한다."와 같은 고객과의 소통을 중요시하는 문항들로 구성되어 ‘상호작용성'으로 명명하였다. 요인 3은 “소 셜커머스에서 곧 품절되려고 하는 의류제품은 즉시 구매하고 싶어진다.”, “소셜커머스 딜에 대한 마감임 박 메시지를 보면 구매해야 한다는 생각이 든다.”, “소셜커머스에서 수량이 제한된 경우, 의류제품을 구 매하고 싶다.”와 같이 제품의 희소성에 관한 메시지 로 구성되어 있어 ‘제품희소성'으로 명명하였으며, 요 인 4는 “소셜커머스의 상품은 온라인 쇼핑몰보다 품
질 대비 가격이 저렴하여 가치가 높다고 생각한다.”, “소셜커머스에서는 온라인 쇼핑몰에 제시된 가격보 다 할인된 가격으로 의류제품을 구입할 수 있다."로 제품의 가격할인과 관련된 문항들로 구성되어 ‘가격 할인'으로 명명하였다.

\section{Consumer's personal characteristics}

20 30대 남성 소비자의 개인적 특성에 대한 하위 차원을 분류하기 위해 탐색적 요인분석을 실시하였으 며, 결과는 〈Table 3〉과 같다. 분석방법으로는 Varimax 회전법의 주성분 분석(principle component analysis) 을 실시하였으며, 총 14 개의 문항 중 3 개의 요인을 추출하였다. 이 요인들은 전체 변량의 $65.792 \%$ 의 설 명력을 가지고 있으며, 신뢰도를 나타내는 Cronbach's $\alpha$ 값이 .80이상으로 나타나 신뢰할만 하였다. 20 30 대 남성의 개인적 특성에 관한 요인 1은 “소셜커머스

$<$ Table 3> The result of factor analysis about consumer's personal characteristics

\begin{tabular}{|c|c|c|c|c|c|c|}
\hline Factor & Measurement item & $\begin{array}{c}\text { Factor } \\
\text { loadings }\end{array}$ & $\begin{array}{l}\text { Eigen } \\
\text { value }\end{array}$ & $\begin{array}{c}\text { Variance } \\
(\%)\end{array}$ & $\begin{array}{l}\text { Accumulative } \\
\text { variance }(\%)\end{array}$ & $\begin{array}{l}\text { Reliability } \\
(\%)\end{array}$ \\
\hline \multirow{6}{*}{ Interest } & I have much curiosity about social commerce. & .764 & \multirow{6}{*}{3.312} & \multirow{6}{*}{23.657} & \multirow{6}{*}{23.657} & \multirow{6}{*}{.843} \\
\hline & $\begin{array}{l}\text { I deeply concentrate on social commerce when I visit } \\
\text { there. }\end{array}$ & .680 & & & & \\
\hline & I am interested in using social commerce. & .751 & & & & \\
\hline & I like to search the information in social commerce. & .763 & & & & \\
\hline & I am familiar with social commerce. & .696 & & & & \\
\hline & I am interested in buying product in social commerce. & .574 & & & & \\
\hline \multirow{4}{*}{$\begin{array}{c}\text { Tendency } \\
\text { of } \\
\text { impulse } \\
\text { buying }\end{array}$} & $\begin{array}{l}\text { I have a tendency to contemplate before buying in social } \\
\text { commerce. (R) }\end{array}$ & .734 & \multirow{4}{*}{3.053} & \multirow{4}{*}{21.808} & \multirow{4}{*}{45.465} & \multirow{4}{*}{.856} \\
\hline & $\begin{array}{l}\text { I have a experience to buy today's special price product } \\
\text { immediately. }\end{array}$ & .854 & & & & \\
\hline & $\begin{array}{l}\text { Even if big discount is provided in social commerce, } \\
\text { I don't purchase the product if I don't need it. (R) }\end{array}$ & .850 & & & & \\
\hline & I have a experience to buy the product without planning. & .760 & & & & \\
\hline \multirow{4}{*}{$\begin{array}{c}\text { Internet } \\
\text { shopping } \\
\text { experience }\end{array}$} & $\begin{array}{l}\text { I am familiar with buying the product via internet } \\
\text { shopping mall. }\end{array}$ & .771 & \multirow{4}{*}{2.846} & \multirow{4}{*}{20.327} & \multirow{4}{*}{65.792} & \multirow{4}{*}{.858} \\
\hline & $\begin{array}{l}\text { I have buying experience in internet shopping mall before } \\
\text { buying in social commerce. }\end{array}$ & .864 & & & & \\
\hline & $\begin{array}{l}\text { I think it is easy to use social commerce because of } \\
\text { buying experience in internet shopping mall. }\end{array}$ & .787 & & & & \\
\hline & $\begin{array}{l}\text { More buying experience to have in internet shopping } \\
\text { mall, it is easier to buy the product in social commerce. }\end{array}$ & .815 & & & & \\
\hline
\end{tabular}

$\mathrm{R}$ (Riverse) means reverse coding. 
에 대해서 호기심이 많다”, “소셜커머스를 방문하다 보면 나도 모르게 완전 몰두하게 된다.”, “소셜커머스 를 통한 구매에 관심이 많다.”와 같이 소셜커머스에 대한 관심과 흥미와 관련된 문항들로 구성되어 '흥미 도'로 명명하였으며, 요인 2는 “소셜커머스에서 오늘 의 특가제품을 충동적으로 구매한 경험이 있다”, “소 셜커머스에서 파는 의류 제품에 대해 세심한 계획을 세우지 않고, 제품을 구매한 경험이 있다.”와 같이 충 동구매와 관련되는 문항들로 구성되어 '충동구매성 향'으로 명명하였다. 요인 3은 “나는 인터넷 쇼핑을 통해 제품을 구매하는데 익숙하다.”, “소셜커머스에 서 의류제품을 구입하기 전에 인터넷 쇼핑을 통해 구 입한 경험이 있다.", “나는 인터넷 쇼핑을 한 경험이 있으므로 소셜커머스 서비스의 사용법은 쉽게 느껴 진다.”와 같이 인터넷 쇼핑에서의 제품의 구매 경험 을 중요시하는 문항들로 구성되어 '인터넷 쇼핑경험' 으로 명명하였다.

\section{Repurchase intention}

구매의도의 하위차원을 분류하기 위해 탐색적 요 인분석을 실시하였으며, 결과는 〈Table 4〉와 같다. 분 석방법으로는 Varimax 회전법의 주성분 분석(principle component analysis)을 실시하였으며, 총 4 개의 문항 중 1 개의 문항을 제거하여 총 3 개 문항의 1 개의 요인 을 추출하였다. 이 요인들은 전체 변량의 $80.771 \%$ 의 설명력을 가지고 있으며, 신뢰도를 나타내는 Cronbach's $\alpha$ 값이 .80 이상으로 나타나 신뢰할만 하였다. 재구 매 의도에 관한 요인 1 은 "나는 소셜커머스에서 제품 을 재구매할 가능성이 높다.”, “나는 소셜커머스에서 제시된 금액으로 제품의 재구매를 고려할 것이다."와 같이 제품의 재구매 의사와 관련되는 문항들로 구성 되어 '재구매 의도'로 명명하였다.

\section{Word-of-mouth intention}

구전의도의 하위차원을 분류하기 위해 탐색적 요 인분석을 실시하였으며, 결과는〈Table 5〉와 같다. 분 석방법으로는 Varimax 회전법의 주성분 분석(principle component analysis)을 실시하였으며, 총 3 개의 문항 의 1 개의 요인을 추출하였다. 이 요인들은 전체 변량 의 $73.632 \%$ 의 설명력을 가지고 있으며, 신뢰도를 나 타내는 Cronbach's $\alpha$ 값이 .80 이상으로 나타나 신 뢰할만 하였다. 구전의도에 관한 요인 1 은 “지인들 에게 내가 이용한 소셜커머스를 추천할 것이다.”, "나는 소셜커머스를 통한 구매에 대해 긍정적으로

$<$ Table $4>$ The result of factor analysis on repurchase intention

\begin{tabular}{|c|c|c|c|c|c|c|}
\hline Factor & Measurement item & $\begin{array}{c}\text { Factor } \\
\text { loadings }\end{array}$ & $\begin{array}{l}\text { Eigen } \\
\text { value }\end{array}$ & $\begin{array}{l}\text { Variance } \\
(\%)\end{array}$ & $\begin{array}{l}\text { Accumulative } \\
\text { variance }(\%)\end{array}$ & $\begin{array}{l}\text { Reliability } \\
(\%)\end{array}$ \\
\hline \multirow{3}{*}{$\begin{array}{l}\text { Repurchase } \\
\text { intention }\end{array}$} & $\begin{array}{l}\text { I have a high possibility to repurchase the product } \\
\text { in social commerce. }\end{array}$ & .877 & \multirow{3}{*}{2.423} & \multirow{3}{*}{80.771} & \multirow{3}{*}{80.771} & \multirow{3}{*}{.879} \\
\hline & $\begin{array}{l}\text { I consider to buy the product at suggested price } \\
\text { in social commerce again. }\end{array}$ & .932 & & & & \\
\hline & $\begin{array}{l}\text { I have a intention to repurchase the product in } \\
\text { social commerce. }\end{array}$ & .886 & & & & \\
\hline
\end{tabular}

$<$ Table 5> The result of factor analysis on word-of-mouth intention

\begin{tabular}{|c|c|c|c|c|c|c|}
\hline Factor & Measurement item & $\begin{array}{c}\text { Factor } \\
\text { loadings }\end{array}$ & $\begin{array}{l}\text { Eigen } \\
\text { value }\end{array}$ & $\begin{array}{l}\text { Variance } \\
(\%)\end{array}$ & $\begin{array}{l}\text { Accumulative } \\
\text { variance }(\%)\end{array}$ & $\begin{array}{l}\text { Reliability } \\
(\%)\end{array}$ \\
\hline \multirow{3}{*}{$\begin{array}{l}\text { Word-of-mouth } \\
\text { intention }\end{array}$} & $\begin{array}{l}\text { I will recommend the social commerce I use } \\
\text { to others. }\end{array}$ & .890 & \multirow{3}{*}{2.209} & \multirow{3}{*}{73.632} & \multirow{3}{*}{73.632} & \multirow{3}{*}{.852} \\
\hline & $\begin{array}{l}\text { I will say positively buying the product in } \\
\text { social commerce. }\end{array}$ & .811 & & & & \\
\hline & $\begin{array}{l}\text { I will speak about the benefit of buying the } \\
\text { product in social commerce to others.. }\end{array}$ & .871 & & & & \\
\hline
\end{tabular}


말할 것이다.”와 같이 소셜커머스에서 제품구매 후 구전과 관련된 문항들로 구성되어 '구전의도'로 명 명하였다.

6. The influence of social commerce characteristics on repurchase intention and word-of-mouth intention

소셜커머스 특성이 20 30대 남성의 재구매의도에 미치는 영향에 대해 회귀분석을 한 결과(Table 6), 사 이트 명성도, 상호작용성, 제품희소성이 재구매의도 에 영향을 미치는 것으로 나타나, 가설 H1-1, H1-2, $\mathrm{H} 1-3$ 는 지지되었으며 전체 설명력( $\left.\operatorname{Adj~} R^{2}\right)$ 은 $38.8 \%$ 로 나타났다. 네 개의 변인 중 사이트 명성도 $(\beta=222$, $t=3.101, p<.01)$ 는 가장 큰 정 $(+)$ 적 영향을 미치는 것 으로 나타났다.

소셜커머스 특성이 20 30대 남성의 구전의도에 미 치는 영향에 대해 회귀분석을 한 결과(Table 7), 사이 트 명성도, 상호작용성, 가격할인이 구전의도에 영향 을 미치는 것으로 나타나, 가설 $\mathrm{H} 2-1, \mathrm{H} 2-2, \mathrm{H} 2-4$ 는 지지되었으며, 전체 설명력( $\left.\operatorname{Adj} R^{2}\right)$ 은 $24.8 \%$ 로 나타 났다. 네 개의 변인 중 사이트 명성도 $(\beta=333, t=4.702$, $p<.001)$ 와 상호작용성 $(\beta=250, t=3.522, p<.01)$ 이 가
장 큰 정 $(+)$ 의 영향을 미치는 것으로 나타났다.

이와 같은 결과는 가상의 공간에서의 불확실성으 로 인해 소셜커머스 사이트의 평판이 중요하다는 $\mathrm{Kim}$ (2012)의 연구결과를 지지했으며, 상호작용성에 있어 서는 고객과의 소통이 중요하다는 $\operatorname{Kim}(2012)$ 의 연구 결과와 빠른 주문처리와 배송과 같은 고객서비스가 중요하다는 Lee et al.(2012)의 연구와 일치하였다. 그 러나 가격요인은 20 30대 남성 소비자의 재구매 의 도에 영향을 주는 변인으로 나타나지 않았는데, 이는 오픈 마켓도 가격할인을 많이 하여 차별성을 잃어 현 재는 가격할인 요인보다는 소셜커머스의 다른 특성 이 소비자의 재구매 의도에 영향을 미치는 변인으로 나타나, 가격 요인이 중요하다는 Lee(2014)의 연구결 과와 차이점을 보였다.

7. The influence of consumer's personal characteristics on repurchase intention and word-of-mouth intention

20 30대 남성의 소비자의 개인적 특성이 재구매의 도에 미치는 영향을 알아보기 위해 회귀분석을 한 결 과(Table 8), 사이트 흥미도, 충동구매성향이 재구매의 도에 영향을 미치는 것으로 나타나 가설 H3-1, H3-2는

$<$ Table 6> The influence of social commerce characteristics on repurchase intention

\begin{tabular}{|c|c|c|c|c|c|c|c|c|}
\hline \multirow{2}{*}{\multicolumn{2}{|c|}{ Variables }} & \multicolumn{2}{|c|}{ U.S.C } & \multirow{2}{*}{$\begin{array}{c}\text { S.C } \\
\beta\end{array}$} & \multirow{2}{*}{$t$} & \multirow{2}{*}{$p$} & \multirow{2}{*}{$F$} & \multirow{2}{*}{$\begin{array}{c}R^{2} \\
\left(\operatorname{adj} R^{2}\right.\end{array}$} \\
\hline & & $\mathrm{B}$ & S.E & & & & & \\
\hline \multirow{4}{*}{$\begin{array}{l}\text { Repurchase } \\
\text { intention }\end{array}$} & Website reputation & .201 & .065 & .222 & $3.101^{* *}$ & .002 & \multirow{4}{*}{$\begin{array}{l}35.288 \\
(.000)\end{array}$} & \multirow{4}{*}{$\begin{array}{c}.399 \\
(.388)\end{array}$} \\
\hline & Interactivity & .228 & .082 & .200 & $2.787^{* *}$ & .006 & & \\
\hline & Product scarcity & .261 & .087 & .207 & $3.008^{* *}$ & .003 & & \\
\hline & Price reduction & -.058 & .081 & -.054 & -.713 & .476 & & \\
\hline
\end{tabular}

${ }^{*} p<.05, \quad{ }^{* *} p<.01, * *^{*} p<.001$

$<$ Table 7> The influence of social commerce characteristics on word-of-mouth-intention

\begin{tabular}{|c|c|c|c|c|c|c|c|c|}
\hline \multirow{2}{*}{\multicolumn{2}{|c|}{ Variables }} & \multicolumn{2}{|c|}{ U.S.C } & \multirow{3}{*}{$\begin{array}{c}\text { S.C } \\
\beta \\
.333\end{array}$} & \multirow{3}{*}{$\begin{array}{c}t \\
4.702^{* * *}\end{array}$} & \multirow{3}{*}{$\begin{array}{c}p \\
.000\end{array}$} & \multirow{3}{*}{$F$} & \multirow{2}{*}{$\begin{array}{c}R^{2} \\
\left(\operatorname{adj} R^{2}\right)\end{array}$} \\
\hline & & B & S.E & & & & & \\
\hline \multirow{4}{*}{$\begin{array}{l}\text { Word-of-mouth } \\
\text { intention }\end{array}$} & Website reputation & .314 & .067 & & & & & \multirow{4}{*}{$\begin{array}{c}.262 \\
(.248)\end{array}$} \\
\hline & Interactivity & .296 & .084 & .250 & $3.522^{* *}$ & .001 & \multirow{3}{*}{$\begin{array}{l}19.182 \\
(.000)\end{array}$} & \\
\hline & Product scarcity & .150 & .089 & .115 & 1.682 & .094 & & \\
\hline & Price reduction & -.176 & .083 & -.157 & $-2.121^{*}$ & .035 & & \\
\hline
\end{tabular}

${ }^{*} p<.05, \quad{ }^{* *} p<.01, \quad{ }^{* * *} p<.001$ 
<Table 8> The influence of consumer's personal characteristics on repurchase intention

\begin{tabular}{|c|c|c|c|c|c|c|c|c|}
\hline \multirow{2}{*}{\multicolumn{2}{|c|}{ Variables }} & \multicolumn{2}{|c|}{ U.S.C } & \multirow{3}{*}{$\begin{array}{c}\text { S.C } \\
\beta \\
.228\end{array}$} & \multirow{2}{*}{$t$} & \multirow{2}{*}{$p$} & \multirow{2}{*}{$F$} & \multirow{2}{*}{$\begin{array}{c}R^{2} \\
\left(\operatorname{adj} R^{2}\right)\end{array}$} \\
\hline & & B & S.E & & & & & \\
\hline \multirow{3}{*}{$\begin{array}{c}\text { Repurchase } \\
\text { intention }\end{array}$} & Interest & .273 & .091 & & $3.068 * *$ & .002 & \multirow{3}{*}{$\begin{array}{l}23.206 \\
(.000)\end{array}$} & \multirow{3}{*}{$\begin{array}{c}.301 \\
(.288)\end{array}$} \\
\hline & Tendency of impulse buying & .232 & .076 & .224 & $2.987 * *$ & .003 & & \\
\hline & Internet shopping experience & -.022 & .066 & -.023 & -.333 & .740 & & \\
\hline
\end{tabular}

${ }^{*} p<.05,{ }^{* *} p<.01,{ }^{* * *} p<.001$

지지되었으며, 전체 설명력( $\left.\operatorname{Adj} R^{2}\right)$ 은 $28.8 \%$ 로 나타 났다. 두 개의 변인 중 흥미도 $(\beta=228, t=3.068, p<.01)$ 가 더 큰 정 $(+)$ 의 영향을 미치는 것으로 나타났다.

20 30대 남성의 소비자의 개인적 특성이 구전의도 에 미치는 영향을 알아 보기 위해 회귀분석을 한 결과 (Table 9), 흥미도와 인터넷 쇼핑경험이 구전의도에 영 향을 미치는 것으로 나타나 가설 H4-1, H4-3은 지지되 었으며, 전체 설명력(Adj $R^{2}$ )은 $31.3 \%$ 로 나타났다. 두 개의 변인 중 인터넷 쇼핑경험 $(\beta=223, t=3.300, p<.01)$ 이 더 큰 정 $(+)$ 의 영향을 미치는 것으로 나타났다.

이와 같은 결과는 소셜커머스에서 재구매 의도와 구전의도 모두에 영향을 미치는 변수로 20 30대 남 성소비자의 개인적인 특성 중 흥미도가 중요함을 알 수 있었고, 소셜 커머스에서 일반 제품구입 시 흥미 성이 구매행동에 영향을 준다는 Kwon, Kim, Park, \& Lee(2011)의 연구와 인터넷에서 패션제품 구매 시 사 이트에 대한 흥미와 호기심이 높을수록 구매율이 높 아진다는 $\operatorname{Baek}(2008)$ 의 연구결과를 지지하였다.

\section{Conclusion}

본 연구는 소셜네트워크 서비스가 보편화되고, 모 바일 커머스의 성장과 함께 짧은 기간 빠르게 동반 성장한 소셜커머스에서의 소비자 구매행동 관련 연
구가 필요한 시점에서 소셜커머스에서 주요 소비자 로 급부상하고 있는 20 30대 남성을 대상으로 패션 제품과 관련하여 소셜커머스에서의 재구매 의도와 구전의도에 영향을 미치는 변인을 살펴 본 연구로써 그 의의가 있다고 하겠다.

본 연구의 결과를 요약하면 다음과 같다.

첫째, 소셜커머스 특성을 유형화하기 위해 요인분 석을 한 결과, 사이트 명성도, 상호작용성, 제품희소 성, 가격할인의 4 가지 요인으로 추출되었고, 소비자 의 개인적 특성은 흥미도, 충동구매성향, 인터넷 쇼핑 경험과 같은 3 가지 요인으로 나타났다.

둘째, 소셜커머스의 특성(사이트 명성도, 상호작용 성, 제품희소성, 가격할인)이 20 30대 남성의 재구매 의도와 구전의도와 미치는 영향을 알아본 결과, 사이 트 명성도, 상호작용성, 제품희소성이 재구매 의도에 영향을 미치며, 구전의도에 영향을 주는 변인으로는 사이트 명성도, 상호작용성, 가격할인으로 나타났다. 4 개의 요인 중 사이트 명성도와 상호작용성은 재구매 의도와 구전의도 모두에 영향을 미치는 중요 변수임 을 확인하였다.

셋째, 소비자의 개인적 특성(흥미도, 자기통제성, 인터넷 쇼핑경험)이 소셜커머스에서 패션제품을 구매 시 재구매 의도와 구전의도에 미치는 영향을 알아본 결과, 재구매 의도에는 흥미도와 충동구매성향이 영향

$<$ Table 9> The influence of consumer's personal characteristics on word-of-mouth-intention

\begin{tabular}{|c|c|c|c|c|c|c|c|c|}
\hline \multirow{2}{*}{\multicolumn{2}{|c|}{ Variables }} & \multicolumn{2}{|c|}{ U.S.C } & S.C & \multirow{2}{*}{$t$} & \multirow{2}{*}{$p$} & \multirow{2}{*}{$F$} & \multirow{2}{*}{$\begin{array}{c}R^{2} \\
\left(\operatorname{adj} R^{2}\right)\end{array}$} \\
\hline & & $\mathrm{B}$ & S.E & $\beta$ & & & & \\
\hline \multirow{3}{*}{$\begin{array}{l}\text { Word-of-mouth } \\
\text { intention }\end{array}$} & Interest & .287 & .091 & .231 & $3.140 * *$ & .002 & \multirow{3}{*}{$\begin{array}{l}34.393 \\
(.000)\end{array}$} & \multirow{3}{*}{$\begin{array}{c}.322 \\
(.313)\end{array}$} \\
\hline & Tendency of impulse buying & .133 & .076 & .124 & 1.760 & .080 & & \\
\hline & Internet shopping experience & .219 & .066 & .223 & $3.300 * *$ & .001 & & \\
\hline
\end{tabular}

${ }^{*} p<.05, \quad{ }^{* *} p<.01, * *{ }^{*} p<.001$ 
을 주었으며, 구전의도에는 흥미도와 인터넷 쇼핑경 험이 영향을 미치는 것으로 나타나, 소셜커머스에서 20 30대 소비자의 재구매 의도와 구전의도에 모두에 영향을 주는 개인적 특성은 소셜커머스에 대한 흥미 도로 나타났다.

본 연구를 토대로 한 마케팅적 시사점은 다음과 같 다.

첫째, 20 30대 남성의 개인적 특성 중 흥미도 요인 이 재구매 의도와 구전의도에 모두에 영향을 미치는 요인이므로 소셜커머스 업체 담당자들은 소비자들에 게 소셜커머스 사이트에서 관심과 즐거움을 제공하 여 흥미를 유발할 수 있는 마케팅 전략을 수립하여야 할 것이다. 예를 들어 20 30대를 타겟으로 한 $\mathrm{MD}$ 추 천의 단독 브랜드나 제품을 개발하는 전략으로 오프 라인 매장에서 활발하게 시행되고 있는 판매촉진처 럼 'Only for social commerce'를 홍보하며, 특정 대 형 할인점의 전유물이었던 유통업자 상표(Private Brand: $\mathrm{PB})$ 를 소셜커머스에서도 런칭하여 소셜커머스에 대 한 흥미도를 유발시켜야 할 것이다.

둘째, 20 30대 남성이 중요시하는 소셜커머스 특 성 중 사이트명성도와 상호작용성이 재구매 의도와 구전의도에 영향을 미치는 것으로 나타났다. 따라서 아직은 짧은 역사를 가진 소셜 커머스가 안정적으로 정착하기 위해서는 $1: 1$ 맞춤형 서비스를 강화하여 상 호작용성을 높이고, 소셜커머스를 이용하여 공동구매 를 하는 제품이 정상제품과의 차별대우를 받는다거 나, 환불정책의 부당함과 같은 소비자 불만족과 불편 을 최대한 줄일 수 있도록 신뢰할 수 있는 사이트 명 성도를 구축해야 할 것이다.

셋째, 20 30대 남성소비자는 컴퓨터 보다는 스마 트폰 앱을 통한 소셜커머스 이용률이 높으므로 소셜 커머스 업체는 작은 화면에서 타겟 소비자를 겨냥한 $\mathrm{MD}$ 추천의 제품 큐레이션과 함께 소비자의 관심과 몰 입도를 높일 수 있는 스마트폰에 최적화된 웹사이트 구축에 힘써야 할 것이다.

본 연구의 한계점은 다음과 같다.

첫째, 본 연구에서는 연구대상자 선정은 서울과 경 기지역에 거주하는 20 30대 남성으로 제한하였기 때 문에, 연구결과를 일반화시키기에는 대표성의 한계점 이 있다 향후에는 다양한 연령층의 남성소비자를 대상 으로 연구 대상자를 확대할 필요성이 있다고 하겠다.
둘째, 소비자의 개인적 특성에 관한 선행연구의 부 족으로 소비자의 개인적 특성 변수를 세 가지로 제한 하였기 때문에, 향후에는 소비자의 개인적 특성변수 에 대한 더 세밀한 연구가 필요하리라 생각된다.

셋째, 본 연구는 소셜커머스의 다양한 제품군 중에 서 패션제품으로 한정으로 하여 연구하였기 때문에, 현재 소셜커머스에서 전개하고 있는 전체 제품군으 로 연구결과를 확대 해석할 때에는 신중을 기해야 할 것이다.

\section{References}

Ahn, T. H. (2015). 최근 온라인쇼핑 트렌드와 대응전 략 [Recent trends and strategies of online shopping]. Retail CEO Report, 18, 1-23.

An, U. S. (2013). An effect of social commerce motivations on customer loyalty: Focused on social commerce provider trust and social commerce supplier trust. Journal of Korea Service Management Society, 14(5), 201-228.

Bae, J. K. (2013). A study of influencing factors for repurchase intention in social commerce services. The e-Business Studies, 14(2), 199-224.

Baek, M.-Y., \& Han, S.-L. (2015). Analysis of usage motivation and repeat-using intention in mobile social commerce. Korean Journal of Business Administration, 28(1), 103-120.

Baek, S. R. (2008). The influence of impulse buying tendency, apparel price and scarcity message on purchasing behavior at the time of group buying on the internet. Unpublished master's thesis, Sungkyunkwan University, Seoul, Korea.

Chae, S. H., Lim, J. I., \& Kang, J. Y. (2015). A comparative analysis of social commerce and open market using user reviews in Korean mobile commerce. Journal of Intelligence and Information Systems, 21(4), 53-77. doi:10.13088/jiis.2015.21. 4.053

Chen, Q. (2012). A study on the influential factors of students' impulsive purchases in social commerce. Unpublished master's thesis, Sejong University, 
Seoul, Korea.

Cho, H. J., Shin, S. J., \& Song, J. G. (2012). 소셜커 머스 환경에서 구매만족에 영향을 미치는 요인에 관한 연구 [A study on the influential factors of consumer satisfaction in social commerce]. Journal of the Korean Society of Management Information System, 2012(1), 1092-1100.

Choi, Y.-J., \& Lee, M.-A. (2016). Effects of characteristics of social commerce on purchase intention: Moderating effects of perceived risk and price sensitivity of mobile application users. Journal of the Korean Society of Clothing and Textiles, 40(3), 574-589. doi:10.5850/JICSCT.2016.40.3.574

Crego, E. T., \& Schiffrin, P. D. (1995). Customercentered reengineering: Remapping for total customer value. Burr Ridge, Illinois: Irwin Professional Pub.

Dellarocas, C. (2003). The digitization of word of mouth: Promise and challenges of online feedback mechanisms. Management Science, 49(10), 14071424. doi:10.1287/mnsc.49.10.1407.17308

Goo, D. S. (2011), 국내 소셜커머스 기업 마케팅 분 석을 통한 $\mathrm{SNS}$ (Social Network Service) 활용방 안에 관한 연구 [A study on the SNS(Social Network Service) utilization through domestic social commerce company marketing analysis]. Unpublished master's thesis, Ajou University, Gyeonggi-do, Korea.

Han, E.-K., Song, S.-J., \& Lim, H.-N. (2011). The motives for using social commerce and satisfaction, repurchase intention: Based on the uses and gratification theory. The Korean Journal of Advertising and Public Relations, 13(3), 298-325.

Han, S.-L., \& Park, C.-K. (2000). Determinants of consumer buying intention in online environment: Analysis of flow concept. Journal of Korean Marketing Association, 15(1), 187-204.

Hong, J.-B., \& Lee, S.-H. (2015). The influence of social commerce characteristics on reliability and repurchase intention after purchasing sports products. The Korea Journal of Sports Science, 24(6), 767-779.
Hwang, S.-J., \& Baek, S.-R. (2009). The influence of impulse buying tendency, price, and scarcity message on apparel choice and purchase intention at the time of internet group buying. Journal of the Korean Society of Clothing and Textiles, 33(10), 1519-1529. doi:10.5850/JKSCT.2009.33.10.1519

Jin, D. S., \& Lim, J. W. (2012). Impacts of social commerce in e-commerce: In perspective of social commerce analysis model. International Commerce and Information Review, 14(1), 369-390.

Jin, G.-S., \& Lee, J.-H. (2012). Service quality factors affecting satisfaction and repurchase intention of social commerce. The Journal of the Korea Contents Association, 12(3), 311-321. doi:10.5392/JKCA.=2012. 12.03.311

Jung, J. S. (2014, December 19). 모바일 쇼핑... ‘나는 소셜커머스 vs 기는 오픈마켓' [Mobile shopping... 'fly social commerce VS crawl open market']. $M K$ news, Retrieved September 26, 2016, from http:// news.mk.co.kr/newsRead.php?year $=2014 \&$ no $=154$ 8009

Kang, D. W. (2016, March 09). 2015 온라인쇼핑 시 장규모 $\cdots$ 인터넷쇼핑 29조, $\mathrm{M}$ 커머스 24조 달성 [2015 on-line shopping mall market size $\cdots$ Internet shopping mall 2900 billion, M-commerce 2400 billion achieve]. Money today, Retrieved September 26, 2016, from http://mnb.moneys.news/mnbview. php?no=2016030810318094036

Kim, H. (2016, July 21). 쿠팡, 남성 구매자 2년새 $64 \%$ 급증... ‘男心 홀린 소셜커머스' [Coupang, man customer increase $64 \%$ during 2 years... 'social commerce attract man's mind']. Financial news, Retrieved September 26, 2016, from http://www. fnnews.com/news/201607211413345424

Kim, H. J., \& Chung, M. S. (2015). The effects of clothes shopping orientation and perceived risk on purchase intention in social commerce. The Research Journal of the Costume Culture, 23(3), 384-399. doi:10.7741/rjcc.2015.23.3.384

Kim, I., \& Son, M. J. (2013). A study on consumer purchasing behavior of brand-name fashion goods 
via social commerce. Journal of Basic Design \& Art, 14(4), 143-155.

Kim, K. S. (2013). Social commerce motivations, benefits and dissatisfaction factors the impact on the buying behavior loyalty. Korean Journal of Consumer and Advertising Psychology, 14(2), 343-364.

Kim, M.-S. (2012). Effects of motivation and reputation on customers' participation, trust, behavior intention in social commerce sites. Unpublished doctoral dissertation, Yeungnam University, Gyeongsangbuk-do, Korea.

Kim, S. H., \& Oh, S. H. (2002). Examining the relationship of virtual satisfaction, virtual trust, and virtual loyalty in the internet shopping. The Journal of Social Science, 21(2), 109-125.

Kim, T. H. (2016, April 15). 소셜커머스, 영업손실 8313 억... “적자는 성장통" [The loss of 831.3 billion won in social commerce... "Its deficit represents growing pains"]. Seoul Finance, Retrieved April 17, 2016, from http://www.seoulfn. com/news/articleView.html?idxno $=250305$

Kozinets, R. V., De Valck, K., Wojnicki, A. C., \& Wilner, S. J. S. (2010). Networked narratives: Understanding word-of-mouth marketing in online communities. Journal of Marketing, 74(2), 71-89. doi:10.1509/jmkg.74.2.71

Kwon, H.-I., Kim, M.-J., Park, J.-H., \& Lee, J.-A. (2011). Study on evaluation of social commerce quality: Focus on quality factors of the information system and individual characteristics. Journal of Korean Institute of Information Technology, 9(8), 229-237.

Lee, A.-R. (2012). Researching the effect that purchasing factor of social commerce have on customer satisfaction, customer loyalty and repurchasing. Unpublished master's thesis, Kyunghee University, Seoul, Korea.

Lee, E. M. (2011). 소셜 커머스 글로벌 사업자 동향 [Social commerce global business trends]. Korea Information Society Development Institute, 23(3),
36-44.

Lee, H. J. (2014). A study on purchase satisfaction and repurchase intention according to usage motivation when purchasing fashion products in social commerce. Fashion \& Textile Research Journal, 16(4), 596-603. doi:10.5805/SFTI.2014.16.4.596

Lee, J.-H. (2013). The influence of social commerce characteristics on satisfaction, reliability and repurchase intention. Journal of Distribution and Management Research 16(2), 103-113.

Lee, M.-J., Chung, S.-J., \& Jeon, Y.-J. (2012). A study on satisfaction and intention to re-purchase fashion goods through social commerce. Journal of the Korea Fashion \& Costume Design Association, 14(2), 63-74.

Lee, S.-J., \& Shin, S.-Y. (2013). A study on the influential factors of impulsive purchases by female university students in their 20's when purchasing fashion products in social commerce. Fashion \& Textile Research Journal, 15(5), 743-752. doi:10.5805/SFTI. 2013.15.5.743

Park, E. J., Kim, E. Y., Funches, V. M., \& Foxx, W. (2012). Apparel product attributes, web browsing, and e-impulse buying on shopping websites. Journal of Business Research, 65(11), 1583-1589. doi:10. 1016/j.jbusres.2011.02.043

Park, M. Y. (2015, April 15). 공룡이 된 소셜커머스, 5년 새 거래액 이렇게나... [Social commerce became a dinosaur, for 5 years, trade amounts become $\cdots$ ]. Digitaltimes, Retrieved September 26, 2016, from http://www.dt.co.kr/contents.html?article_no= 2015041502109976798005

Park, S. C., \& Koh, J. (2013). Determinants of continuance intention to use social commerce for group purchasing: The moderating role of product involvement. Entrue Journal of Information Technology, 12(2), 139-154.

Shin, J.-M., \& Yoh, E. A. (2013). The effect of consumer innovativeness on repurchase intention of fashion products through social commerce. Journal of Living Science Research, 39, 91-101. 
Shin, S. A (2012). Comparison of flow and loyalty of travelers using social commerce based on their motives and impulse buying tendencies. Unpublished master's thesis, Kyungsung University, Busan, Korea.

Son, M.-J. (2013). A study on consumer purchasing behavior of brand-name fashion goods via social commerce. Unpublished master's thesis, Kookmin University, Seoul, Korea.

Stephen, A. T., \& Toubia, O. (2010). Deriving value from social commerce networks. Journal of Marketing Research, 47(2), 215-228. doi:10.1509/ jmkr.47.2.215

Trusove, M., Buckling, R. E., \& Pauwels, K. (2009). Effect of word-of-mouth versus traditional marketing: Findings from an internet social networking site. Journal of Marketing, 73(5), 90-102. doi:10. 1509/jmkg.73.5.90

Wang, Y., \& Kwon, S.-D. (2012). A study on the factors influencing repurchase intention in social commerce. Journal of Information Technology Applications \& Management, 19(4), 137-152.

Wangenheim, F. V., \& Bayón, T. (2007). The chain from customer satisfaction via word-of-mouth referrals to new customer acquisition. Journal of the Academy of Marketing Science, 35(2), 233-249. doi:10.1007/s11747-007-0037-1

Woo, S. H., \& Hwang, J. S. (2013). The effect of fashion consumer's browsing motives and risk perception on purchase intention in social commerce. Journal of the Korean Society of Clothing and Textiles, 37(6), 772-785. doi:10.5850/JKSCT.2013. 37.6 .772

Yang, H. S., \& Choi, E. J. (2014). The effect of shopping value on fashion shopping satisfaction and future behavioral intention in fashion social commerce. Journal of the Korean Society of Clothing and Textiles, 38(3), 293-304. doi:10.5850/JKSCT. 2014.38.3.293 